\title{
Percepções sobre um Processo de Software sob o Ponto de Vista das Equipes de Desenvolvimento: Um Estudo de Caso
}

\author{
Trabalho Técnico
}

\author{
Jose Jorge L. Dias Jr. ${ }^{1,2}$, Andson Felipe P. Belo ${ }^{1}$, Fernanda N. M. Dias ${ }^{2}$ \\ ${ }^{1}$ Centro de Ciências Aplicadas e Educação - Universidade Federal Paraíba (UFPB) \\ Rio Tinto - PB - Brasil \\ ${ }^{2}$ Núcleo de Educação a Distância da UFPB - Universidade Federal Paraíba (UFPB) \\ João Pessoa - PB - Brasil \\ \{jorge, andson.belo\}@dce.ufpb.br, fernanda.nmdias@gmail.com
}

\begin{abstract}
One of the first steps to start a software improvement process is to understand how the current process is perceived by the development teams. In this sense, this work presents a case study, supported by a qualitative method, in a public company. It aims at verifying the compreehesion, usefulness, importance and use of software process from viewpoint of development teams. Hence, a thematic and categorial content analysis was performed. The results evidence problems related to aspects of learning and use of the process.
\end{abstract}

Resumo. Um dos primeiros passos ao iniciar um processo de melhoria de software é entender como o processo atual é percebido pelas equipes de desenvolvimento. Neste sentido, este trabalho apresenta um estudo de caso, apoiado por uma metodologia qualitativa, em uma empresa pública com o objetivo de verificar se o processo de software é compreendido, útil, importante e utilizado adequadamente sob o ponto de vista das equipes de desenvolvimento. Para isso foi utilizada o método de Análise de Conteúdo temática categorial. Os resultados evidenciam problemas relacionados principalmente a aspectos da aprendizagem e utilização do processo.

\section{Introdução}

A engenharia de software é uma área que abrange camadas (ferramentas, métodos, processo) fundamentadas em um comprometimento organizacional com a qualidade. Além disso, o processo de software é o que mantém estas camadas coesas, possibilitando o desenvolvimento racional do software [Pressman 2011].

Neste sentido, é importante que exista uma metodologia para estabelecer o alicerce de um processo de desenvolvimento do software dentro da organização, pois colocar o foco no processo aumenta a qualidade e consequentemente aumenta a competitividade entre as empresas através da melhoria dos produtos de software [MPS.BR 2012].

No entanto, existem alguns fatores que podem influenciar negativamente a adoção de um processo de software, entre elas, tecnologias, características da empresa, fatores humanos, entre outros [Montoni e Rocha 2010]. Além disso, a engenharia de software é entendida como uma disciplina de natureza sociotécnica, baseada na forte 
interação entre fatores pessoais, sociais e técnicos [Sawyer 2004]. De acordo com McMenamin (1996) e DeMarco \& Lister (1999), as pessoas possuem uma tendência natural para resistirem a mudanças. Neste sentido, ao se adotar um processo de software, é importante tentar entender que fatores irão impedir a efetiva utilização deste. Assim, possíveis dificuldades técnicas e resistência da equipe podem ser obstáculos para a adoção do processo de software e consequentemente causar o insucesso de projetos.

Muitas empresas de software vêm buscando a aderência a modelos de melhoria de processos, tais como CMMi e MPS.BR, a fim de alcançar um maior nível de qualidade de seus processos e consequentemente de seus produtos. Entretanto, entendemos que o primeiro passo para atingir este objetivo é verificar qual a percepção das equipes em relação ao processo atual, para entender, por exemplo, se ele é realmente conhecido, compreendido, utilizado, considerado útil e entender possíveis barreiras para sua efetiva adoção.

Nesta direção, este artigo expõe um estudo de caso sobre as percepções de duas equipes sobre o processo de desenvolvimento utilizado em uma instituição pública de tecnologia. Mais especificamente, nosso objetivo é responder a seguinte questão de pesquisa: "Qual a percepção da equipe em relação ao entendimento, utilização, utilidade e importância do processo de software definido pela empresa?". Para isso, foi realizada uma pesquisa qualitativa através de um estudo de caso seguindo um rigor científico de acordo com as orientações de Yin (2010). Para a análise dos dados utilizou-se a análise de conteúdo temática categorial apresentada por Bardin (1979).

Esse artigo está organizado da seguinte forma: a Seção 2 apresenta os trabalhos relacionados, principalmente em relação a aplicação de metodologias com rigor científico para a melhoria de processo de software. Na Seção 3 é apresentada a metodologia utilizada neste trabalho com o plano, estratégia de coleta de dados e método de análise. A Seção 4 discute os resultados da análise do estudo de caso. $\mathrm{Na}$ seção 5 estão as considerações finais e trabalhos futuros.

\section{Trabalhos Relacionados}

Dos Santos (2011) apresenta um trabalho que trata de uma análise qualitativa que prioriza os aspectos humanos influenciadores em um programa de melhoria de processo de software (MPS). Com o propósito de obter melhor entendimento sobre as questões que influenciam programas de MPS, a análise realizada no referido trabalho é baseada nos procedimentos da Teoria Fundamentada nos Dados, na qual, segundo Schots (2010), propõe um conjunto de procedimentos para gerar, elaborar e validar teorias sobre fenômenos ou processos essencialmente sociais. Para obtenção de dados foram conduzidas entrevistas em empresas pioneiras na implementação do MPS.BR no estado do Amazonas entretanto o trabalho se limita a aspectos do comportamento organizacional sugerido por Robbins (2005).

Em Menolli (2011) é realizado um estudo exploratório sobre as percepções dos gerentes de projeto em relação às práticas do modelo MPS em Fábricas de Software no Brasil. O objetivo, com isto, é avaliar a expectativa destes gerentes em relação a importância das práticas de qualidade propostas pelo modelo MPS. Além disso, confronta as práticas e as frequências com que são utilizadas no desenvolvimento dos seus projetos. Para realização desse trabalho foi adaptado um instrumento, 
SERVQUAL, para avaliar a qualidade do serviço por meio da análise da expectativa e da percepção sobre o serviço, entretanto, o estudo foca apenas na fase de codificação e na percepção dos gerentes de projeto.

Um outro trabalho relacionado é o de Montoni (2010) que apresenta um estudo qualitativo baseado na Teoria Fundamentada nos dados, conduzido no intuito de investigar, na perspectiva de consultores de organizações de consultoria, as iniciativas de implementação de melhoria em processos de software. O resultado deste estudo é uma teoria construída com o propósito de explicar o fenômeno associado ao sucesso destas iniciativas, porém, as influencias negativas, que poderiam ser abordadas no sentido de evitá-las, não são consideradas.

Todos estes trabalhos apresentaram certo rigor metodológico para investigar diferentes aspectos. A engenharia de software carece de trabalhos com este rigor e por isto a presente pesquisa avança neste sentido.

Diferentemente dos trabalhos apresentados, este procurou compreender os aspectos que podem influenciar a aderência a um processo de software, considerando os aspectos humanos e técnicos sem se limitar as características de um programa específico de melhoria de software, porém podendo contribuir para aderi-lo.

\section{Metodologia}

O objetivo geral desta pesquisa é analisar um processo de software com o propósito de entender as percepções em relação ao seu aprendizado, utilização, importância e dificuldades do ponto de vista das equipes de desenvolvimento no contexto de uma empresa pública.

Para isso, foi realizada uma pesquisa qualitativa através de um estudo de caso seguindo um rigor científico seguindo as orientações de Yin (2010). O estudo de caso se se dá por um processo linear, mas iterativo possuindo as seguintes etapas [Yin 2010]: Plano; Projeto; Preparação; Coleta; Análise e Compartilhamento. A seguir estas etapas são explicadas detalhadamente.

\subsection{Contexto}

Esta pesquisa foi executada em uma empresa pública especializada em tecnologia da informação, que para este trabalho é uma unidade de análise. O escopo da empresa é o desenvolvimento e suporte de sistemas de informação de qualidade, a segurança das informações que estes armazenam e o provimento da eficiência, segurança e disponibilidade da rede institucional de computadores. Ao todo a empresa possui cerca de mais de 50 colaboradores. Para fins de confidencialidade este trabalho não divulgará o nome da empresa, apenas identificando-a como E.T.I (Empresa de Tecnologia da Informação).

A E.T.I definiu seu processo de software há algum tempo, baseado no Scrum e também tem o objetivo de alcançar o nível $G$ do modelo MPS.BR. Mas antes disso, é necessário entender como o processo atual está sendo percebido pelas equipes de desenvolvimento. Esta iniciativa partiu do departamento de testes da E.T.I. 


\subsection{Plano e Projeto do Estudo}

O respaldo para a definição das unidades de análise, bem como a seleção das questões mais importantes para a empresa foram definidas, principalmente pela ajuda da líder do Departamento de Testes, que auxiliou na identificação das questões que poderiam ser essenciais para o problema da pesquisa, que até o momento era a aderência ao MPS.BR. No entanto, um problema que antecede a aderência ao primeiro nível do MPS.BR é a aderência ao processo. Portanto os esforços foram direcionados a entender como o atual processo é percebido pelas equipes.

Inicialmente, foi realizado um levantamento bibliográfico, onde foram considerados livros, artigos científicos, dissertações e teses acadêmicas. Em seguida, o estudo de caso foi cuidadosamente planejado e executado.

Para reforçar a validade do constructo foi decidido por utilizar múltiplas fontes de evidência para que os dados possam ser triangulados, entre elas, observação, entrevistas e análise documental do processo de software. Além disso, houve uma preocupação com a confiabilidade da pesquisa e por isso um protocolo de pesquisa foi definido para que todos os envolvidos tenham a clareza de todos os procedimentos metodológicos a serem utilizados, como por exemplo, os roteiros de entrevista e de observação. O protocolo também é importante uma vez que possibilita a replicação da pesquisa em outros casos. Os detalhes deste instrumento podem ser solicitados diretamente aos autores.

As entrevistas são fontes essenciais por que retratam assuntos humanos ou comportamentais. Os entrevistados podem gerar insights importantes sobre os assuntos ou eventos. Foi utilizado um roteiro de entrevistas semi-estruturado onde foi inicialmente concebido de maneira colaborativa entre a equipe de pesquisa e a gerente de testes. Esta última exerceu uma influência importante no sentido de adicionar questões que fossem relevantes do ponto de vista interno da empresa. As questões foram baseadas principalmente nas observações realizadas e nas informações fornecidas pela gerente de testes.

\subsection{Preparação e Coleta de dados}

Após o refinamento das questões, o roteiro de entrevista foi submetido a um teste-piloto onde foram identificadas oportunidades de melhorias, tanto em relação ao próprio roteiro quanto em relação a postura do pesquisador diante do entrevistado. Este último é uma colaboradora da empresa, portanto possui propriedade para responder as questões, mas não faz parte de nenhuma das duas equipes selecionadas para a análise. Portanto, sua entrevista não é considerada para a geração dos resultados.

A coleta das entrevistas ocorreu entre janeiro e fevereiro de 2014 e envolveu 07 profissionais de 02 equipes Por uma questão de sigilo, os participantes foram identificados com códigos que variaram entre P001 a P007, bem como as equipes foram identificadas como equipe A e equipe B.

A seleção dos entrevistados foi baseada na oportunidade, portanto, por conveniência, uma vez que eles estavam participando de dois projetos na E.T.I que utilizavam o processo. 
Tabela 1. Informações sobre as posições dos entrevistados e seus respectivos tempos das entrevistas

\begin{tabular}{|c|c|c|c|}
\hline ID & CARGO & EQUIPES & TEMPO DE ENTREVISTA \\
\hline P001 & Técnico de tecnologia da informação & \multirow{3}{*}{ Equipe - A } & $00 \mathrm{~h}: 24 \mathrm{~m}: 06 \mathrm{~s}$ \\
\hline P002 & Técnico de tecnologia da informação & & 00h:15m:06s \\
\hline P003 & Técnico de tecnologia da informação & & $00 \mathrm{~h}: 20 \mathrm{~m}: 38 \mathrm{~s}$ \\
\hline P004 & Analista de tecnologia da informação & \multirow{4}{*}{ Equipe - B } & 00h:31m:04s \\
\hline P005 & Técnico de tecnologia da informação & & $00 \mathrm{~h}: 19 \mathrm{~m}: 54 \mathrm{~s}$ \\
\hline P006 & Técnico de tecnologia da informação & & $00 \mathrm{~h}: 15 \mathrm{~m}: 26 \mathrm{~s}$ \\
\hline P007 & Técnico de tecnologia da informação & & 00h:16m:00s \\
\hline
\end{tabular}

$\mathrm{Na}$ observação participante, o observador assume um papel na situação de estudo de caso e participa nos eventos sendo estudados [Yin 2010]. Em nossa pesquisa, as equipes foram observadas em relação as atividades cotidianas durante outubro de 2013 e janeiro de 2014. As observações foram registradas em um diário do pesquisador.

Além das atividades cotidianas, também foram feitas observações em reuniões. O observador manteve sigilo em relação a sua observação para não influenciar e causar viés aos que estavam sendo observados.

Também foi realizada a análise documental sobre informações do processo atual. A empresa utiliza uma Wiki para documentar o processo e os projetos. Portanto foi dado acesso ao pesquisador para poder realizar esta análise na Wiki.

\subsection{Análise dos dados}

Segundo Olabuenaga e Ispizúa (1989), a análise de conteúdo é uma técnica para ler e interpretar o conteúdo de toda classe de documentos, que analisados adequadamente nos abrem as portas ao conhecimento de aspectos e fenômenos da vida social de outro modo inacessível.

Cada tipo de técnica de desenvolvimento da análise do conteúdo permite a exploração do material analisado. A análise temática categorial, um tipo de análise de conteúdo, tenta encontrar, a partir de temas e categorias que representam significações no texto, equivalências em função da apreensão do investigador [Pêcheux 1993]. Deve abranger todo o texto, submetendo-o a um crivo de classificação e quantificação pela frequência de presença ou ausência de itens de sentido. Funciona por um desmembramento do texto que visa classificar elementos comuns em unidades ou categorias [Oliveira 2008].

A Figura 1 apresenta as etapas, baseadas em Oliveira (2008), executadas para a realização da análise.

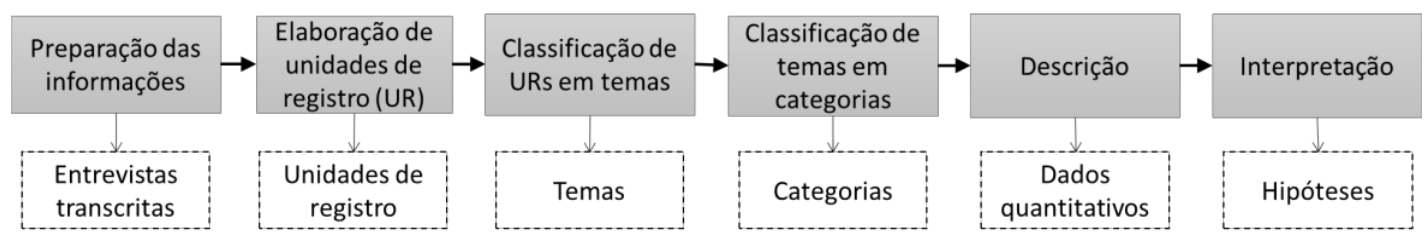

Figura 1: Etapas da análise 
Todos os áudios das entrevistas foram transcritos para serem analisados e codificados. A partir destas transcrições foram elaborados Unidades de Registro (UR), que correspondem ao segmento da entrevista que possui algum significado para o objeto em estudo. Para isso foram realizadas marcações no texto para cada UR observada. Em seguida, foi realizada a análise temática através da criação de temas para representar cada UR. Os temas que possuíam o mesmo sentido foram condensados. Portanto, cada UR foi associado a um ou mais temas, sendo que cada tema pode ser composto por um conjunto de URs.

Depois da análise temática, foi realizada a análise categorial, onde os temas são agrupados segundo critérios teóricos ou empíricos, originando conceitos macros, denominadas categorias. Cada tema é associado a apenas uma categoria, sendo que cada categoria contêm um conjunto de temas que tem significaos relacionados. A Figura 2 ilustra este esquema para uma melhor compreensão. Na figura podemos visualizar duas URs que originaram o tema "Recursos insuficientes de aprendizagem". Na análise categorial, este tema e outros com ideias relacionadas, originaram a categoria "Aprendizagem sobre o processo".

$\mathrm{Na}$ etapa de descrição, o objetivo é comunicar o resultado quantitativo das etapas anteriores, ou seja, apresentar a quantificação dos temas ou unidades de significação em número de URs. Finalmente, na etapa de Interpretação é realizada a análise qualitativa, em busca da compreensão das evidências. Neste passo, são construídas inferências com base nos dados e nas categorias de análise.

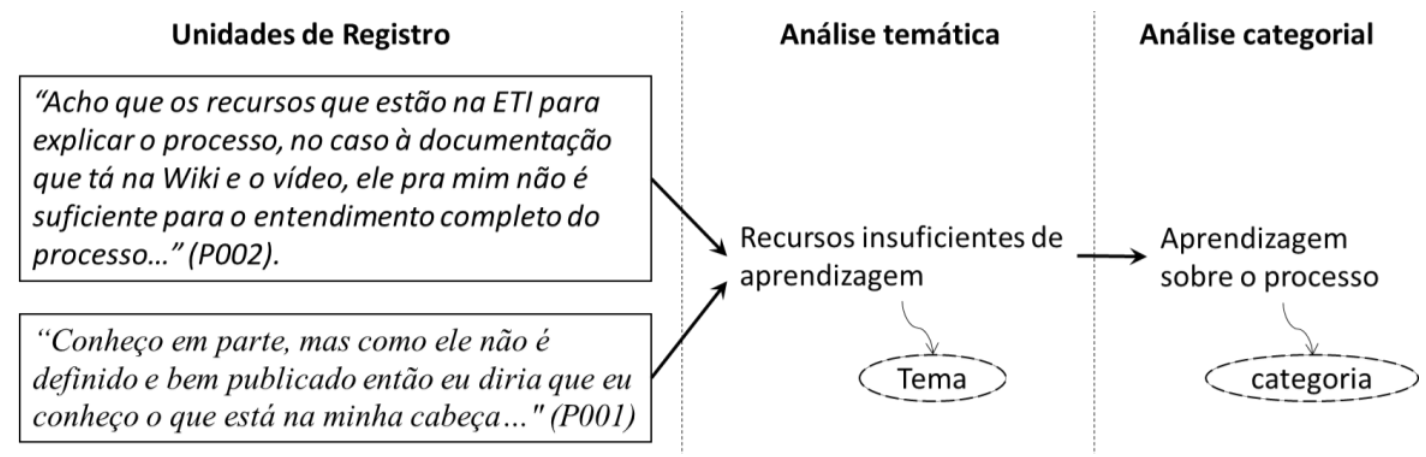

Figura 2 - Exemplo de Unidades de Registro, tema e categoria

$\mathrm{Na}$ primeira análise foram gerados 111 temas. Entretanto, para aumentar a validade interna da pesquisa foram aplicadas duas estratégias. Apenas temas que tiveram pelo menos duas fontes (URs) foram considerados para o estudo. Além disso, caso houvesse contradição entre a UR e o diário do pesquisador ou análise documental, a UR era desconsiderada. Neste sentido, ao final foram gerados 17 temas e 05 categorias.

\section{Resultados}

A Tabela 2 apresenta o resultado da análise temática e categorial das entrevistas onde são definidas as dimensões nas quais os temas aparecem, agrupadas em categorias. Percebemos claramente a frequência maior nas categorias "Aprendizagem sobre o processo" e "Ferramentas". 
Sendo assim, verifica-se a partir da quantificação, apresentada pela Tabela 2, que o tema mais recorrente refere-se a "Esforço para utilizar a wiki". Este e os outros temas foram denominados a partir das URs. Neste sentido, quatro dentre as sete pessoas entrevistadas falaram sobre o esforço que exercem para utilizar a wiki da empresa.

Outros temas que apareceram em seguida foram: "Padronização das atividades", "Melhoria na qualidade do software", "Execução de procedimentos não institucionalizados", "Importância do Redmine" e "Ajustes do processo". Cada um destes temas possui três URs.

Outros temas que apareceram foram: "Recursos insuficientes de aprendizagem", "Definição do processo", "Aprendizado através da prática", "Conhecimento transferido por pessoas", "Disponibilização da documentação na wiki", "Definição das responsabilidades", "Abandono do processo em momentos de crise", "Falta de aderência ao Scrum", "Utilização limitada do Redmine", "Falta de Conhecimento do Hudson", "Meta para aderir o MPS.BR".

Tabela 2. Análise categorial do texto, adaptado de Oliveira (2008)

\begin{tabular}{|c|c|c|c|c|}
\hline $\begin{array}{l}\text { TEMAS/UNIDADE DE } \\
\text { SIGNIFICAÇÃO }\end{array}$ & $\begin{array}{l}\mathbf{N}^{\mathbf{o}} . \mathbf{U R} / \\
\text { TEMA }\end{array}$ & CATEGORIAS & $\begin{array}{c}\mathbf{N}^{\mathbf{o}} . \mathrm{UR} / \\
\text { CATEGORIA }\end{array}$ & $\begin{array}{c}\% \text { UR/ } \\
\text { CATEGORIA }\end{array}$ \\
\hline $\begin{array}{c}\text { Recursos insuficientes de } \\
\text { aprendizagem }\end{array}$ & 2 & \multirow{5}{*}{$\begin{array}{l}\text { Aprendizagem } \\
\text { sobre o processo }\end{array}$} & \multirow{5}{*}{10} & \multirow{5}{*}{24,4} \\
\hline Definição do processo & 2 & & & \\
\hline Aprendizado através da prática & 2 & & & \\
\hline Conhecimento transferido por pessoas & 2 & & & \\
\hline $\begin{array}{c}\text { Disponibilização da documentação na } \\
\text { wiki }\end{array}$ & 2 & & & \\
\hline Definição das responsabilidades & 2 & \multirow{3}{*}{$\begin{array}{l}\text { Importância do } \\
\text { processo }\end{array}$} & \multirow{3}{*}{8} & \multirow{3}{*}{19,5} \\
\hline Padronização das atividades & 3 & & & \\
\hline Melhoria na qualidade do software & 3 & & & \\
\hline $\begin{array}{l}\text { Execução de procedimentos não } \\
\text { institucionalizados }\end{array}$ & 3 & \multirow{3}{*}{$\begin{array}{l}\text { Utilização do } \\
\text { processo }\end{array}$} & \multirow{3}{*}{7} & \multirow{3}{*}{17,1} \\
\hline $\begin{array}{l}\text { Abandono do processo em momentos } \\
\text { de crise }\end{array}$ & 2 & & & \\
\hline Falta de aderência ao Scrum & 2 & & & \\
\hline Importância do Redmine & 3 & \multirow{4}{*}{ Ferramentas } & \multirow{4}{*}{11} & \multirow{4}{*}{26,8} \\
\hline Utilização limitada do Redmine & 2 & & & \\
\hline Esforço para utilizar a wiki & 4 & & & \\
\hline Falta de conhecimento do Hudson & 2 & & & \\
\hline Ajustes do processo & 3 & \multirow{2}{*}{$\begin{array}{l}\text { Amadurecimento } \\
\text { do processo }\end{array}$} & \multirow{2}{*}{5} & \multirow{2}{*}{12,2} \\
\hline Meta para aderir o MPS.BR & 2 & & & \\
\hline
\end{tabular}

O resultado pode ser influenciado pelo roteiro de entrevista, ainda assim, ações que visem a melhoria das questões que envolvem o aprendizado do processo bem como as ferramentas previstas no processo podem surtir efeito positivo para as equipes de software e para a empresa. É importante ressaltar que pode existir relação entre as 
categorias, de modo que uma impacte na outra, por exemplo, "Aprendizagem sobre o processo" pode impactar na "Utilização do Processo", da mesma forma que o tema "Esforço para utilizar a wiki" que corresponde à categoria "Ferramentas" pode impactar na "Disponibilização da documentação na Wiki" que por sua vez corresponde à categoria "Aprendizagem do Processo". As categorias "Importância do processo" e "Amadurecimento do processo" respectivamente podem demonstrar certa motivação para amadurecer ou melhorar o processo.

Nas subseções a seguir serão apresentados os resultados referentes à etapa de Interpretação. Para cada categoria identificada serão apresentadas inferências baseadas na interpretação dos dados.

\subsection{Aprendizagem sobre o processo}

Através dos relatos, verificou-se que há uma documentação sobre o processo e os projetos. Esta documentação está em uma Wiki e percebe-se que ela é reconhecida pelas equipes como a fonte de informações sobre o processo.

- "Temos uma ferramenta de documentação que a gente usa que é a MediaWiki, é onde são disponibilizadas as informações mais teóricas digamos assim, (..) as informações mais conceituais do projeto, o que é o projeto, quem participa, quais são os objetivos, isso a gente documenta na Wiki...". (P004)

- "Acho que são importantes sim, a wiki como falei, ela concentra todas as informações, ela é um pouco dificil de manter, esse é um ponto negativo dela, mas ela é importante sim. Ela concentra tudo de informação que a gente precisa para manter o projeto está lá, é uma fonte muito boa de informações”. (P006)

Mesmo com as informações sobre o processo disponíveis em uma Wiki, foi percebido que os recursos necessários para aprender sobre o processo são insuficientes, gerando a falta ou o entendimento parcial sobre o processo.

- "Acho que os recursos que estão na ETI para explicar o processo, no caso à documentação que tá na Wiki e o vídeo, ele pra mim não é suficiente para o entendimento completo do processo. Eu também acho que não entendo completamente". (P002).

- "Conheço em parte, mas como ele não é definido e bem publicado então eu diria que eu conheço o que está na minha cabeça, mas fora isso eu não tenho como definir se eu conheço mais detalhes". (P001)

O que reforça a proposição acima é que alguns membros mais antigos da equipe aprenderam sobre o processo sem ajuda da documentção e sim porque participaram da sua concepção, participando de reuniões de definição e melhorias do processo. Outros aprenderam de acordo com a demanda e o andamento do projeto, na prática.

- “... em algum lugar lá da wiki tá esse processo, na parte de desenvolvimento e processo. Mas assim, no final das contas eu aprendi pelo fato de tá participando das reuniões e tá ajudando também na criação do processo." (P005).

- "Para mim foi suficiente justamente por eu ter participado das discussões e da produção desse processo..." (P001)

- “... então para mim é suficiente por que eu adquiri o aprendizado ali com todas as discussões, as motivações, para mim isso é suficiente por que eu aprendi fazendo o software, mas para outras pessoas pode não ser." (P001). 
Entretanto, novos membros que entram na empresa não tem o mesmo conhecimento sobre o processo e precisam aprender sobre esse. Como foi constatado que os recursos para a auto-aprendizagem são escassos, deveria haver um treinamento para os novos membros. Entretanto, percebe-se que não existe uma política de treinamento de maneira consolidada. Como consequência, os membros mais antigos precisam ensinar informalmente aos novos membros. Entretanto, o conhecimento pode não ser passado da maneira correta. Além disso, os membros antigos tornam-se mais improdutivos nas suas atividades por ter que alocar um tempo para ensinar aos novos.

- “... eu acho que no início deveria ter um treinamento assim, para a pessoa que está entrando. Mas atualmente não tem tido tempo por que tá todo mundo muito atarefado, tem poucas pessoas para os projetos e aí não tem muito tempo de tá fazendo o treinamento. E ai a pessoa vai se adaptando com o tempo mesmo." (P007).

- “... a gente sente essa dificuldade quando chega um novo membro na equipe (...). Então quando a gente tenta explicar esses passos, a pessoa entende aqueles passos ali, mas não é algo bem definido, por exemplo, eu posso esquecer algum detalhe e aí quando outra pessoa da equipe vai tentar explicar ou discutir sobre o mesmo assunto, ele também já lembra de outros detalhes, justificativas por que é importante aquela atividade, aquela etapa (...) quem chega que não participou das discussões e das definições é bem mais difícil." (P001)

- "Quando eu cheguei à ETI o pessoal ainda estava na fase de elaboração desse processo, então acho que tudo que eles faziam tudo que eles decidiam em reunião eles comunicavam para gente e ai a gente passava a seguir." (P006)

- "As 09h30min P001 mesmo estando de férias apareceu na sala e sentou para trabalhar juntamente com um novato que chegou no mesmo horário, estes mantiveram-se em contato de forma que P001 parecia instruir o outro". (Diário do Pesquisador-07/01/2014).

\subsection{Importância do processo}

As evidências mostraram que as pessoas entendem a importância de seguir o processo, e reconhecem que a qualidade do processo influencia na qualidade do produto gerado. Este é um ponto importante, pois possibilita a aceitação de um processo bem definido e diminui a resistência para sua utilização.

- "Eu gosto do processo, eu acho que ele consegue dar a qualidade que o software precisa no final. O objetivo dele é esse, é proporcionar pro usuário a qualidade de software que ele espera, e eu acho que o processo consegue dar por que ele tem várias fases: testes, concepção, desenvolvimento. E eu acho que quando o software passa por todos estes ciclos ele consegue chegar ao final do jeito que o cliente espera não cem por cento, mas eu acho que é um nivel aceitável o software que sai hoje da ETI passando pelo processo ele chega ao final com um nível de qualidade aceitável." (P006).

- "Ele é útil com certeza. Ele é útil por que a gente percebeu que com o uso dele a gente conseguiu aumentar a qualidade do software que a gente entrega para o cliente, diminuiu o número de reclamações, diminuiu o número de bugs, por exemplo, antes existia bugs em produção que era reportado pelos clientes, agora é muito dificil isso acontecer, antes tinha bem mais casos." (P001). 
- “... Ele ajuda (...) a melhorar a qualidade também dos produtos que são desenvolvidos para a comunidade.” (P005).

Além disso, os relatos mostram que os membros têm consciência de que o processo auxilia na definição dos papéis e responsabilidades e na padronização das atividades que precisam ser executadas, podendo trazer uma maior produtividade.

- "É útil sim. Eu acho que valida as nossas tarefas: quem faz o que, a responsabilidade." (P002).

- "Ajuda justamente no que eu falei, em manter a equipe coesa e cada um sabendo das suas responsabilidades dentro dos processos, fica claro o que cada um tem que fazer o que deve ser feito, por que quando não existe processo fica uma coisa meio dispersa, acho que a palavra certa é essa, dispersa!” (P003).

- "Ele ajuda a padronizar o desenvolvimento de software ... "(P005).

- "O processo ele nos ajuda a padronizar as atividades, então quando a gente define um conjunto de atividades, seria o processo, a gente define de acordo com o chefe e com as outras equipes. Então ali padroniza de forma que a minha equipe vai desenvolver daquela forma e as outras equipes também. Então isso ai é um exemplo de como o processo vai ajudar nas nossas atividades, no desenvolvimento." (P001).

- "Quando não tinha esse processo definido era uma coisa meio que ad hoc e cada um fazia da melhor maneira possível. Assim, para ele era a melhor maneira possivel, mas de repente para a equipe toda não era, não trazia uma produtividade. Com o processo isso ai se torna mais unificado, então tem essa importância." (P003).

\subsection{Utilização do processo}

É natural que a aprendizagem sobre o processo influencie positiva ou negativamente na utilização efetiva e correta deste. Isso é percebido através dos relatos sobre a utilização do processo. As equipes tentam seguir atividades ou procedimentos não institucionalizados. Isso pode acontecer por três motivos: a falta ou a má definição de alguns pontos do processo leva a uma tentativa da equipe de melhorá-lo; o desconhecimento e a má aprendizagem sobre o processo leva a equipe a não executar corretamente as atividades, dando uma ideia de que o processo não está adequado àquele cenário; ou ainda, por falta de uma rigorosa política de verificação de conformidade por um setor ou pessoa responsável. Um ponto importante verificado é que os líderes incentivam o uso correto do processo.

- "Eu acho que a equipe ela é muito tendenciosa a fazer o que ela quer, o que ela acha melhor. Então eu acho que se não fosse o trabalho dos líderes sempre incentivando o processo em todas as etapas a equipe não faria. (...) se o líder não bater firme ela não vai usar não. Ela vai tentar atropelar algumas etapas...." (P001).

- “... a gente tem uma sequência de desenvolvimento, mas quando a gente encontra um gargalo em determinado processo a gente tenta sempre se comunicar e ver o que tá errado, adaptar ou mesmo mudar. Então a equipe está flexivel para isso e não forçar que aquela coisa tenha que da certo daquele jeito ali. Se a gente chegar a um consenso de que não é por ali a gente tenta rever os processos e adaptar os processos ou mesmo mudar o processo. Não é que tá acontecendo isso, mas é que a equipe flui de uma maneira que é aberta a esse tipo de ajustes." (P003). 
- "Eu não utilizo o processo de uma maneira ampla. Eu não me preocupo, às vezes, no processo como um todo, então eu julgo que eu não utilizo bem, que eu deveria estar me preocupando no processo como um todo, apesar de eu fazer parte, às vezes, só de uma etapa, mas eu deveria ter uma visão mais macro para que o processo funcionasse." (P002).

Ainda sobre a utilização do processo, houve outros relatos negativos. Percebe-se que há o abandono do processo em momentos de crise, como por exemplo, atrasos no projeto. Apesar de existir uma equipe de qualidade, não existe uma política para garantir a conformidade de um projeto com o processo.

- “... Então tudo que a gente definiu eu tento executar a risca, mas nem sempre acontece tem casos que a gente tem que burlar mesmo, tem que passar algumas etapas para, sei lá, conseguir publicar um conteúdo mais rápido, mas eu tento fazer o máximo possivel." (P001).

- “... então a gente não utilizou de maneira significativa, fizemos uso, mas não de uma forma extensiva, algumas vezes a gente tinha que fugir um pouco do processo para poder atender as demandas de prazo e necessidades dos clientes." (P004).

Para reforçar ainda mais as proposições acima, foi relatado especificamente a falta de aderência a uma das práticas do Scrum, como por exemplo, reuniões diárias. É percebido que a falta das reuniões diárias é prejudicial ao andamento do projeto uma vez que permitem resolver inconsistências e problemas rapidamente, evitando a propagação do erro. Uma das causas pode ser os diferentes horários de trabalho dos membros da equipe.

- "Eu acho que a gente não fazia regularmente as reuniões. Às vezes o pessoal estava fazendo alguma coisa por muito tempo e a reunião demorou muito para acontecer e então outro via que aquilo não deveria ter sido feito. Acho que teve algumas falhas nisso, de não fazer a reunião diária." (P007).

- “... tem as reuniões diárias que é onde é colocado o que cada um está fazendo ou deixou de fazer, se está tendo algum impedimento para realizar as suas tarefas, em relação a isso é que a equipe tem tipo um pouco de falha, por que não está sendo possivel a gente realizar as reuniões diárias por que justamente alguns membros tem horários diferentes de trabalho.. ". (P002)

- "Ao lado do quadro kanban da equipe de desenvolvimento possui papéis colados na parede, em um deles está escrito "reuniões diárias só quando necessário" (Diário do Pesquisador - 30/09/2013).

\subsection{Ferramentas}

Em relação ao uso das ferramentas, há um entendimento da importância da ferramenta Redmine como forma de registrar e acompanhar as atividades planejadas. A ferramenta possibilita que a equipe saiba o que cada um está fazendo em um determinado momento. Percebe-se que não há resistência em utilizá-la.

- "A gente usa o Redmine, eu acho que é importante para registrar tudo o que a gente tá fazendo e às vezes coisas para não esquecer e a gente vai registrando as tarefas lá, eu acho que é muito importante." (P007).

- "O Redmine para registrar as atividades, controle de tempo, controle de prazo, andamento do projeto e ele também é muito importante, além dos bugs da equipe de testes que detecta e reporta para gente através do Redmine." (P006). 
- “... registrar no Redmine, que vai ficar lá o status e eles vão poder acompanhar as minhas tarefas, esse é um papel importante dentro do processo. É registrar o progresso da tarefa que estou executando para que a equipe também saiba como está sendo encaminhada minha tarefa e como está sendo realizado." (P002).

Apesar dos relatos sobre a importância da feramenta Redmine, houve alguns relatos negativos sobre o uso correto dessa. Esta evidência apresenta a falta de procedimentos definidos para o uso do Redmine, como por exemplo, a obrigatoriedade de se registrar algumas informações importantes para possibilitar a gerência efetiva das atividades planejadas.

- “...eu sinto falta de uma melhor utilização da ferramenta [Redmine] por que a ferramenta possui muito recursos inclusive o controle de prazos. Na ferramenta existem projetos onde a gente pode ter um controle de prazo melhor, as equipes atualizam todo dia as tarefas que foram feitas, quanto tempo de cada tarefa foi concluido, mas isso é uma coisa que precisa ser melhorada em nosso processo por que nem todas as equipes seguem esta sistemática com afinco, então a ferramenta é boa mas ela precisa ser melhor utilizada." (P004).

- "Acho que na criação assim, para eles mesmos criarem por que como a gente usa o Scrum, cada um é importante, cada um pode criar tarefas e fazer. Então eles criam só descrevendo as tarefas e pronto, não colocam a quantidade de horas que eles acham que vai demorar, não colocam os detalhes das tarefas e ai a gente vai dizendo que é importante colocar pra saber, pra estimar quanto tempo vai terminar a tarefa, essas coisas assim. Eles têm essa dificuldade em colocar as outras informações além da descrição" (P007).

Em relação à Wiki, foi percebido uma resistência para utilizá-la de maneira efetiva por ser considerada trabalhosa, como por exemplo, para registrar determinados artefatos. Além disso, foi considerada de difícil manutenção devido a exigência de conhecer bem sua linguagem de marcação.

- "A que é um pouco mais complexa, não complexa, mas trabalhosa é a Wiki, mas dificuldade não, ela é mais trabalhosa, mas dificuldade não.” (P005).

- "Especificamente com a wiki eu acho ela um pouco complicada de manter, mas eu também não consigo apontar uma forma melhor de fazer. Eu acho ela dificil de manter por que você tem que escrever em código lá dentro e as ligações entre as coisas as vezes elas se perdem, mas eu não consigo apontar um substituto para ela, então ela atende, tem seus problemas, mas eu não vejo nada melhor do que ela para fazer o que ela faz.". (P006).

- "A questão da wiki é que quando você vai desenvolver os casos de uso, que você vai editar tem a linguagem específica da wiki, que é um pouco verboso por que tem umas tags que a gente tem que usar e ai torna um pouco trabalhoso a edição e a criação desses casos de uso, justamente por causa dessas tags especificas da WIKI. Não é que eu tenha dificuldade, mas é que torna um pouco mais demorado o desenvolvimento desses casos de uso. Basicamente é isso da WIKI especificamente." (P003).

- “... no início eu era das pessoas que mais editava e publicava conteúdo na wiki mas hoje eu já não faço muito isso por conta das minhas atividades e também esses novos recursos eu fico com medo de não conseguir publicar o conteúdo da forma que eu quero usando esse novo recurso que a gente está utilizando na wiki. É uma 
parte que você incluir o conteúdo a partir de um template, e aí tem uma série de parâmetros, aí eu não sei bem como funciona por que às vezes dar errado, então é isso ai que eu tenho mais dificuldade..." (P001)

Em relação a ferramenta de integração continua, percebe-se a falta de conhecimento sobre a teoria e sobre como utilizá-la. Através da análise documental se verifica a falta de procedimentos e documentos sobre como utilizar a ferramenta.

- "Dificuldade de uso não! Mas quando a gente precisa de um recurso mais avançado, por exemplo, do Hudson que é a ferramenta de integração contínua aí a gente fica com mais dificuldade por que se ocorrer algum problema ali que eu precise customizar alguma informação lá no hudson para publicar o sistema eu não saberia fazer, teria que recorrer a alguém que saiba." (P001).

- "Essa de gerência de configuração particularmente eu nunca fiz uso da mesma, preciso até conhecê-la por que em uma necessidade do gerente do projeto não está presente e houver uma necessidade urgente de gerar uma versão. Essa talvez fosse minha maior dificuldade." (P004).

\subsection{Amadurecimento do processo}

O processo foi melhorando com a colaboração das pessoas sugerindo melhorias, e as práticas que eram julgadas positivas para as equipes eram adotadas, o que é importante para a aprendizagem organizacional, no entanto, isso pode ter influenciado as equipes a terem liberdade de alterar o processo no intuito de melhorá-lo ainda hoje.

- "Bem, a gente notou que no dia-a-dia existiam algumas lacunas que a gente foi aprendendo no dia-a-dia e adaptando, até por que o processo é uma coisa que vai sendo adaptada para cada equipe, e foi o nosso caso." (P003).

- "A gente sempre fazia reunião semanal com as equipes de todos os projetos, então lá cada um falava das dificuldades que encontrava no projeto e sempre tinha sugestão de mudança e adequação para que a gente desenvolvesse com mais produtividade e melhor qualidade, então na medida que a gente ia fazendo estes ajustes a gente foi ganhando mais experiência, e também a gente conseguia ver que evoluia...." (P005).

- "Bom, o conhecimento é passado através das reuniões que a gente fazia de acompanhamento e a partir destas reuniões a gente definia as estratégias que seriam: o que fazer, melhores práticas. $E$ ai foi se tornando o processo de desenvolvimento, então a medida que iam sendo identificados os problemas e nessa reunião a gente identificava e discutia e definia as melhores práticas que a gente ia adotar." (P001).

A aderência ao MPS.BR é vista pelas pessoas que reportaram algo a respeito, como uma melhoria ao processo de software da empresa, que é positivo pois além de não demonstrarem nenhuma resistência, expressaram motivação. Como o processo foi sendo amadurecido com o tempo e está em processo contínuo de melhoria, a aderência ao MPS.BR ainda traz consigo a certificação que comprova a qualidade dos processos.

Finalmente, o caso analisado tem o objetivo de atingir o nível $\mathrm{G}$ de maturidade do MPS.BR, e neste sentido, entendemos que o primeiro passo antes de prosseguir para uma aderência ao modelo, é entender qual a percepção dos colaboradores em relação ao atual processo. 
- “... Nós estamos adotando algumas práticas do Scrum, estamos tentando melhorar esse processo continuamente de modo a nós atingirmos o nível G do MPS.BR a médio prazo, algo entre 2014 ou 2015 no máximo".(P004)

- "Veio uma pessoa aqui que implanta o MPS.BR e deu uma explanação para gente e com essa explanação a minha visão é de que o processo de desenvolvimento esta indo do caminho correto, precisa-se fazer os ajustes e as adequações para conseguir a certificação no MPS.BR (...) Mas pela explanação do processo do MPS.BR e pelo que a gente faz hoje, é claro a gente vai precisar ajustar muita coisa para se adequar ao processo, e caso a gente venha a tirar esta certificação vai agregar muito valor a qualidade do software e ao processo de desenvolvimento da gente. (P005).

\section{Considerações Finais}

Esta pesquisa apresentou a condução de um estudo de caso, apoiada em uma metodologia qualitativa, com a finalidade de entender se o processo adotado por uma empresa pública é entendido, considerado importante e utilizado pelas equipes. Para isso foram coletados dados através de entrevistas, observação e análise documental. A confiabilidade das inferências realizadas baseia-se na triangulação dessas diferentes fontes e na frequência de unidades de registro identificadas.

Muitas vezes a alta gerência possui uma ideia errada sobre como o processo é percebido pelas equipes. Portanto, o resultado deste trabalho é importante para o caso analisado pois possibilitou visualizar a real percepção destas equipes, permitindo que ações e estratégias sejam definidas para melhorar os pontos fracos do processo.

Percebemos com este resultado que um dos primeiros passos para aderir a um processo de melhoria de software é fazer com que toda a equipe entenda o processo e a sua importância para que este seja utilizado de maneira natural e não forçada. A empresa analisada deve criar ações e políticas para a melhoria da aprendizagem do processo uma vez que foi evidenciado que os recursos são insuficientes para a autoaprendizagem. Também precisa rever como o processo está estruturado e publicado. Além disso, é importante definir uma política mais rígida de auditoria para garantir que o processo seja seguido e controlado.

Finalmente, entendemos que os objetivos deste projeto foram atendidos e, mesmo que o número de pessoas que participaram da entrevista não seja tão expressivo, o trabalho se torna relevante sob o ponto de vista industrial e acadêmico. Industrial por auxiliar em um caso real uma empresa em direção a uma melhoria de processo de software, e acadêmico, por ter seguido um rigor científico para se obter evidências empíricas, uma vez que há escassez deste tipo de rigor na área de engenharia de software.

Por fim, nossas perspectivas sobre trabalhos futuros envolvem a replicação do estudo apresentado através da aplicação de outros estudos de caso.

\section{Referências}

Bardin, Laurence. (1978). “Análise de conteúdo”. Lisboa: Edições 70. 
Dos Santos, V. et al. (2011). "Programas de Melhoria de Processo de Software - Uma pesquisa sobre a influência dos aspectos humanos". In: Simpósio Brasileiro de Qualidade de Software, Curitiba.

DeMarco, T., Lister, T. (1999). "Peopleware. Productive projects and teams". 2a. ed. Dorset house publishing co. New Yotk.

McMenamin, S. (1996) "The atlantic guide". Londo.

Menolli, A. et al. (2011). "Práticas do Modelo MPS em Fábricas de Software: um estudo exploratório sobre as percepções dos gerentes de projeto". In: Simpósio Brasileiro de Qualidade de Software, 2011, Curitiba.

Montoni, Mariano Angel, and A. R. Rocha. (2010) "Aplicação de Grounded Theory para Investigar Iniciativas de Implementação de Melhorias em Processos de Software." IX Simpósio Brasileiro de Qualidade de Software: 167-182.

MPS.BR (2012). "Melhoria de Processo do Software Brasileiro, Guia Geral". Softex. Disponível em: http://www.softex.br/wpcontent/uploads/2013/07/MPS.BR_Guia_Geral_Software_20121.pdf.

Olabuenaga, J.I. R.; Ispizua, M.A. (1989). "La descodificacion de la vida cotidiana: metodos de investigacion cualitativa". Bilbao, Universidad de deusto.

Oliveira, D. C. (2008) "Análise de conteúdo temático-categorial: uma proposta de sistematização.” Rev. enferm. UERJ, 16(4), 569-576.

Pêcheux M. (1993) “Análise automática do discurso (AAD-69)". In: Gadet F, Hak T, organizadores. Por uma análise automática do discurso: uma introdução à obra de Michel Pêcheux. 2a ed. Campinas (SP): Ed Unicamp. p.61-105.

Pressman, R. S. (2011) "Engenharia de software - Uma abordagem profissional". McGraw Hill - Artmed.

Robbins, S. P. (2005). "Comportamento Organizacional". São Paulo: Prentice Hall.

Sawyer, S. (2004). "Software Teams". Communications of the ACM, v. 47, n. 12, p. 95 99

Schots, N. C. L. (2010). "Uma abordagem para a identificação de causas de problemas utilizando Grounded Theory". Dissertação de Msc., COPPE/UFRJ, RJ.

Yin, R. K. (2010) "Estudo de caso: planejamento e métodos" 4.ed. Porto Alegre: Bookman, 248p; $23 \mathrm{~cm}$. 